\title{
Geometric morphometry of Phytophthora plurivora sporangia
}

\author{
E. Fodor, O. Hâruța, I. Milenković, A. Lyubenova, G. Tziros, N. Keča, S. Slavov, \\ S. Diamandis, K. Kostov
}

Fodor E., Hâruta O., Milenković I., Lyubenova A., Tziros G., Keča N., Slavov S., Diamandis S., Kostov K., 2015. Geometric morphometry of Phytophthora plurivora sporangia. Ann. For. Res. 58(2): 275-294.

Abstract. Eigenshape analysis and Relative Warp Analysis were employed in the study of the shape of highly variable sporangia of Phytophthora plurivora, a widespread oomycetous pathogen isolated from woody species, in several South-East European countries: Bulgaria, Greece, Serbia and Romania. The aim of the study was to estimate whether shape variables permitted the quantitative assessment of sporangial shape variability in $P$. plurivora and also, the discrimination between species based solely on sporangial shape, P. cactorum being selected for comparisons. Both Eigenshape and Relative Warp Analyses showed that the most variable sporangial areas were apical and basal regions. More than half of the shape variation was accounted for the first $2 \mathrm{ES}$ axes $(66.75 \%)$ and first two RW axes $(61.74 \%)$. ESA performed better in terms of species shape (P. plurivora and $P$. cactorum) separation. Canonical Variate Analysis/MANOVA and Discriminant Analysis indicated the clear discrimination between species and between isolates of $P$. plurivora. Mean or consensus shape performed as the best shape descriptor of sporangia. High dimensional variation considered in terms of centroid size corroborated with shape variation spanning from symmetrical consensus shape to conspicuously asymmetric shapes. Keywords Phytophthora plurivora, Phytophthora cactorum, geometric morphometry, eigenshape analysis, relative warp analysis, canonical variate analysis, discriminant analysis, discrepancy index.

Authors. Ecaterina Fodor (ecaterina.fodor@gmail.com), Ovidiu Hâruţa - University of Oradea, Faculty of Environmental Protection, Department of Forestry and Forest Engineering, Gen. Magheru 26, Oradea, Romania; Ivan Milenković - Institute of Forestry, Belgrade, Serbia; Aneta Lyubenova, Slavtcho Slavov, Kaloyan Kostov - AgroBioInstitute Sofia, Bulgaria; Giorgos Tziros, Stephanos Diamandis - NAGREF-Forest Research Institute, Greece; Nenad Keča - University of Belgrade, Department of Forestry, Serbia.

Manuscript received January 16, 2015; revised June 19, 2015; accepted June 29, 2015; online first June 29, 2015. 


\section{Introduction}

The genus Phytophthora, a member of filamentous fungi-like organisms placed in phylum Oomycota, kingdom Straminipila harbors plant pathogens responsible for outbreaks of new and emerging diseases, in natural and man managed ecosystems world-wide, considered to be highly adapted and devastating (Dick 2001, Beakes et al. 2014). Despite their superficial resemblance to fungi, Oomycetes are close to diatoms (Bacillariophytina) and golden brown algae (Ochrophyta) which are opisthokonts (flagellate cells possess posterior flagellum) while fungi are closer to Animalia which are heterokonts (flagellate cells possess two types of flagella) (Lamour et al. 2007). Several harmful Phytophthora species have been identified in forest ecosystems and forest plantations across Europe causing severe forest decline syndromes (Brasier 1996, Jung et al. 1996, Cech 1998, Jung et al. 2000, Jung et al 2003, Jönsson et al. 2003, Oszako \& Orlikovski 2005, Jung \& Burgess 2009, Perlerou et al. 2010, Milenković et al. 2011, Nowakowska et al., 2012, Vitas et al. 2012, Szabo et al. 2013, Lyubenova et al. 2014, Tziros \& Diamandis 2014). It is a difficult group of organisms in terms of identification, as the morphological criteria are scarce, mostly based on morphology of sporangia and gametangia. These in turn are characterized by a higher morphological plasticity and dimensional variation leading to frequent dimensional and shape overlap across species (Brasier 1991).

Phytophthora plurivora was established as a distinct species closely related to $P$. citricola considered a widespread pathogen in natural environments such as forests, streams, but also in man managed plantations and nurseries in Europe, North America. It is also found in nurseries and plantations from Australia and South Africa (Nowakowska et al. 2012, Schoebel et al. 2014). Most affected species are broadleaved trees, recent molecular studies showing that the species is native to Europe
(Schoebel et al. 2014). P. plurivora was associated with chronic oak decline across Europe (Hansen \& Delatour 1999) considered as aggressive pathogen. It is considered a homothallic species presenting one mating type, highly polymorphic and moderately diverse (Nowakowska et al. 2012). Worldwide population structure was assessed as containing 4 distinct clusters which do not correspond to geographical differences (Schoebel et al. 2014).

Sporangia are generally considered as important in identification, but also highly variable within same species, population or sample, hence the reserved consideration of these structures as being entirely reliable. On the other hand, sporangia and zoospores are crucial elements driving the epidemics (Jeger \& Pautasso 2008), representing asexual propagula adapted for abundant and long range dispersal. The propagula are vectored by wind or water, including soil water films (Goodwin 1997).

The species $P$. plurivora, $P$. multivora and $P$. citricola I seem to occupy same ecological niche attacking the fine roots of woody species, causing collar and bark rots and colonizing decaying plant material during the saprotrophic stage. Multiple $P$. citricola like lineages emerged under different climatic conditions and available hosts; it is most probable that the divergence was produced rather recently (Jung \& Burgess 2009).

Identification of plant pathogens made during the last decades tremendous advances due to new genomic and lately, proteomic tools, the main stream in organisms' taxonomical affiliation being moved on molecular territory. However, morphological clues still help in rapid assessment of identity and validate molecular data. Since 1980 major advances were made in the field of geometric morphometrics, the subfield of statistics interested in shape quantification. The advent of coordinate based methods and outline analysis using different approaches, basically fitting functions to characterize the closed or opened curves depicting 
different organisms or parts of organisms represented a major revolution in morphometry (Mitteroecker \& Gunz 2009).

Shape is one of the oldest and yet among most reliable descriptors for species or more generally, item recognition. Particularly, concerning living entities, shape is a large scale expression of many organizing, competing and highly regulated biological processes (Schock $\&$ Perrimon 2002). Shape mirrors environmental constraints and can be analyzed independently from size. It was redefined as the geometric property of a configuration of points which remained unchanged after translation, rotation and scale (Kendall 1989, Slice et al. 1996). When it is combined with dimension, the resulting entity is referred as form. Form and shape spaces are included in the larger phenotypical space characterizing any organism.

Morphometric data can be used to demonstrate ecological variability across populations, provenances or samples at regional scale since shape is a sensitive multivariate quantitative variable permitting the accurate assessment of this kind of variability in a comparable way to molecular approaches. The higher statistical power of morphometric methods in the discrimination of biological entities was repeatedly demonstrated (Jensen at al. 2002, Neustupa \& Št'asný 2006).

A useful group of metrics related to shape diversity and shape dispersion across species or populations, disparity metrics can be employed in conjunction with shape variables. Morphological disparity permits the investigation of shape variation at temporal (phylogenetic) scale and spatial scale (the realm of ecomorphology) (Ricklefs \& Miles 1994). Disparity is considered a complement of biodiversity within the morphospace by detecting the changes in morphospace occupation patterns (Roy \& Foote 1997, Roy et al. 2001, Neige 2003, Neustupa et al. 2009).

We aimed to address the question whether outline and landmark geometric morphometry permits the discrimination among species $(P$. plurivora and $P$. cactorum) and also between samples spanning a diversity of sites. The shape of sporangia in several P. plurivora isolates originating from South-Eastern Europe was analyzed, the work being focused on the construction of a morphospace in which diversity of shapes could be considered and isolates' variability quantitatively assessed. One important goal was to investigate whether subtle morphological differences of sporangia were significant in species discrimination. Another goal was to investigate whether a reference or average, idealized shape, was a reliable morphological descriptor at species and isolate level by eliminating the noise generated by high morphological plasticity.

\section{Materials and methods}

\section{Location of the study}

Phytophthora plurivora T. Jung \& T.I. Burgess was one of the most frequently isolated species during the project SEE-ERA.NET.Plus project ERA 138 "PHYSEE": "Diversity of invading Phytophthora spp. plant pathogens in agro and forest ecosystems in Southeast Europe", covering a large geographical area corresponding to Greece, Serbia, F.Y.R. of Macedonia, Bulgaria and Romania. The investigated material came from locations, tree hosts and ecosystems enumerated in Table 1. These elements could be taken into consideration as environmental variables influencing the ecomorphological variability of sporangia across isolates of $P$. plurivora.

As climatic perspective, Romania, Serbia and Bulgaria are roughly characterized by a temperate continental climate with moderate features: warm summers, long, cold winters, distinct seasonality. In Southern Serbia however, the climate is characterized by dry summers and cold winters. Greece is included in the Mediterranean type of climate with hot and 
Table 1 Locations of the $P$. plurivora and $P$. cactorum samples

\begin{tabular}{|c|c|c|}
\hline Country & Locality and GPS coordinates & Host species and ecosystem type \\
\hline \multicolumn{3}{|l|}{ P. plurivora } \\
\hline Serbia & Avala $(44.689167 ; 20.516111)$ & Fagus sylvatica L. - forest \\
\hline Greece & $\begin{array}{l}\text { Griva (prefecture of Kilkis) (40.954453; } \\
22.411110)\end{array}$ & Castanea sativa Mill.- forest \\
\hline Bulgaria1 & $\operatorname{Tran}(42.834343 ; 22.650370)$ & Alnus glutinosa (L.) Gaertn., riparian forest \\
\hline Bulgaria2 & Tulovo $(42.565130 ; 25.552676)$ & $\begin{array}{l}\text { Quercus robur L., protected area - forest } \\
\text { "Tulovska koriya" }\end{array}$ \\
\hline Bulgaria3 & Velingrad $(42.031131 ; 23.988154)$ & Alnus incana (L.) Moench- city park \\
\hline Romania1 & Caşin (Bacău County) $(46.209127 ; 26.736109)$ & Fagus sylvatica $\mathrm{L}$ - forest \\
\hline Romania2 & $\begin{array}{l}\text { Cluj-Napoca (Cluj County) (46.769589; } \\
\text { 23.576177) }\end{array}$ & Aesculus hippopcastanus L. - city park \\
\hline \multicolumn{3}{|c|}{ P. cactorum } \\
\hline Serbia & Kupinovo (44.440992; 19.591338) & $\begin{array}{l}\text { Juglans regia } \text { L. - protected riparian area } \\
\text { - "Obedska Bara" }\end{array}$ \\
\hline
\end{tabular}

dry summers and cold, wet winters (McKnight \& Hess 2000).

\section{Sampling, isolation and identification of Phytophthora plurivora}

The sampling and isolation/identification protocols were standardized and employed in each laboratory, for all project partners. Rhizosphere soil and tissue samples were collected from symptomless and presenting decline symptoms trees, from different locations placed in Bulgaria, Greece, Romania and Serbia (Milenković et al. 2012, Lyubenova et al. 2012). Samples consisted of soil monoliths of $25 \times 25 \times 25 \mathrm{~cm}$. In the laboratory, subsamples of $400 \mathrm{ml}$ obtained from mixed and homogenized samples, corresponding to each tree were flooded with $600 \mathrm{ml}$ deionized, distilled water. Fresh leaves of Quercus robur, Castanea sativa, Nerium oleander or Fagus sylvatica were placed on water surface to bait the zoospores of Phytophthora species present in the samples (Jung et al. 1996). P. plurivora isolates were retained for geometric morphometric analysis of sporangia of different geographical origin. One isolate of $P$. cactorum originating from Serbia was employed for comparisons, in order to discriminate species based solely on the 278 morphology of sporangia.

Isolation was performed from lesions developed on baited leaves or from diseased tissue, on selective medium - V8-PARPH agar (Jeffers \& Martin 1986, Jung et al. 1996) containing: $50 \mathrm{ml}$ clarified V8 concentrate, $10 \mathrm{mg}$ of Pimaricin, $250 \mathrm{mg}$ of sodium ampicillin, $10 \mathrm{mg}$ of Rifamycin SV, $66.7 \mathrm{mg}$ of pentachlornitrobenzene, $50 \mathrm{mg}$ of Hymexazol, $15 \mathrm{~g}$ of agar and $950 \mathrm{ml}$ distilled water. The Petri plates were incubated in dark, at $22-25^{\circ} \mathrm{C}$, for $3-5$ days and then, the developing colonies were transferred on clarified Carrot Agar (CA) medium (100 ml of clarified carrot juice, $2 \mathrm{~g} \mathrm{CaCO}_{3}, 15 \mathrm{~g}$ agar and $900 \mathrm{ml}$ distilled water). Under the same protocol, took place the incubation of pure cultures used subsequently for morphological identification based on colony characteristics, presence and characteristics of sporangia, oogonia and antheridia. Colony morphology and mycelial growth rate were assessed on $24 \mathrm{~h}$ old cultures on CA, MA and V8 media, grown at room temperature and under a series of cardinal temperatures $(5,10,15,20,25,30$ and $35{ }^{\circ} \mathrm{C}$ ), in triplicates, according to specifications (Erwin \& Ribeiro 1996, Jung \& Burgess 2009). Colony morphology was assessed on 7 to 10 day old cultures. Antheridia and oogonia were obtained in same CA cultures, since both 
Phytophthora species were homothallic.

Production of the sporangia was obtained by flooding fragments of $5 \times 5 \mathrm{~mm}$, from the advancing colony edge of 3-5 days old cultures on CA, with $10 \%$ unsterilized soil solution (Erwin \& Ribeiro 1996, Gallegly \& Hong 2008), placed in Petri plates and incubated for 2-4 days, at room temperature $\left(23-25^{\circ} \mathrm{C}\right)$, under daylight regime. The material was inspected and mature sporangia were removed for observations and photography. In the following days the procedure was repeated until the process of sporangiogenesis has ceased.

Morphological identification of isolates was based on published descriptions and keys (Erwin \& Ribeiro 1996, Jung \& Burgess 2009, Gallegly \& Hong 2008).

Identification at molecular level was based on characteristics of the internally transcribed spacer (ITS) regions of the nuclear ribosomal DNA, the protocol being presented elsewhere (Milenković et al. 2012, Lyubenova et al. 2012, Milenković et al. 2014). Romanian samples were processed for molecular identification at AgroBioInstitute, Sofia using the same standard protocol presented above.

\section{Data acquisition and sporangia shape analysis}

Unstained or acid fuchsine stained sporangia were visualized and photographs of mature sporangia but non-ruptured by zoospore release were digitized by the same person. A total number of 336 microscopic images of Phytophthora plurivora were obtained and processed for all sampling locations. We used same magnification and objective-ocular lenses combination in transmitted light microscopy. However, absolute dimensions not being considered under the present study, the differences between microscopes did not introduce bias in our results. The number of sporangia per sample varied between 26 and 50. The differences in sample size were caused by the higher number of sporangia presenting shape aberrations and the different ontogenetic moments of sporangial development, since sporangia reach maturity in an asynchronous mode.

The images were imported in the software tpsDig, ver. 2.16 (Rohlf 2010) for semiautomatic outline extraction and corresponding coordinate lists (Figure 1).

We employed outline analysis using Eigenshape Analysis (ESA) and landmark based analysis (RWA), techniques that complement each other and give a more thorough account of the analyzed shapes (Francoy et al. 2012). The main result, the consensus shape can be further employed as a benchmark for comparisons across shapes. The obtained shape variables were subjected to multivariate statistical analysis, alone or in combination with the relative dimensional variables (centroid size).
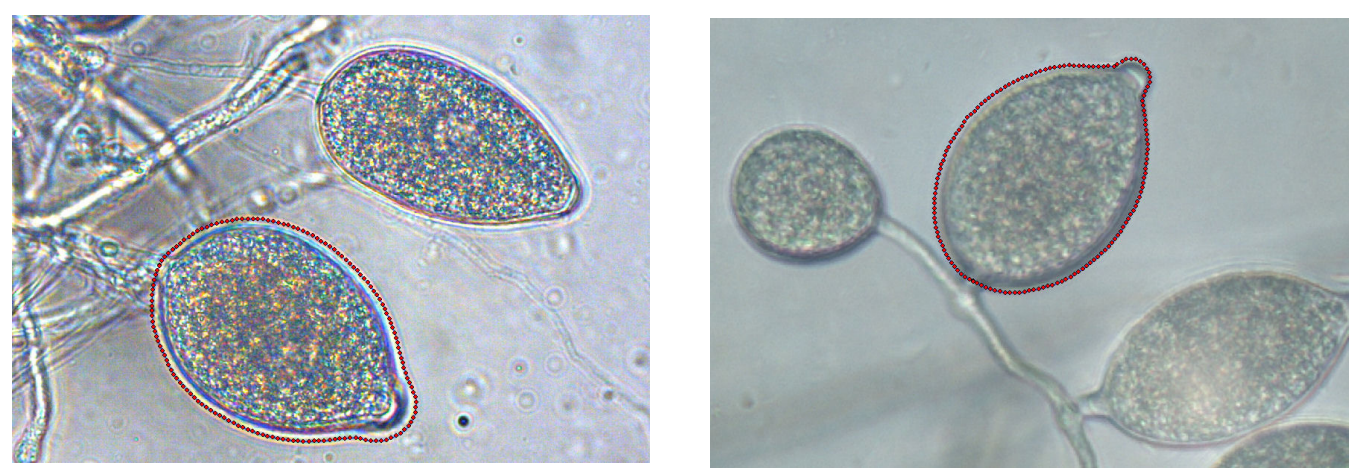

Figure 1 Digitized sporangia of $P$. plurivora (left image) and P. cactorum (right image) 
A different approach for the assessment of sporangial shape diversity encompassing the defined morphospace consisted in the employment of a disparity index devised for this specific goal (Foote 1993). Two control statistics were used, one for accuracy of correlation between Euclidean distances in tangent space and Procrustes distances in Kendall's shape space and one for the accuracy of image digitization (one way ANOVA). All employed analyses and statistics are depicted in Figure 2.

(a) Outline based analysis - Eigenshape analysis. Eigenshape analysis is a technique used for the reduction of digitized outline shapes into few parameters for multivariate analysis and visualization of shape variation (Lohman 1983, Ray 1992, McLeod 2009). The method produces a summary with desirable analytical properties (McLeod \& Rose 1993) such as mutual independence of the shape indices and a direct graphical portrayal. The coordinate points collected from the outline are converted in angles and in phi function. The entire curve is interpolated in standard eigenshape analysis in equally spaced points which become the comparison basis across specimens (McLeod 2012).

Principal Components Analysis was performed in PAST ver. 2.02 (Hammer et al. 2001) on covariance matrix of transformed coordinates using the Zahn-Roskies tangent function (Zahn \& Roskies 1972). The semilandmarks which were more variable across the samples would be more highly weighted. With our data, significant principal axes were selected according to Jolliffe's cut.

We employed 150 evenly spaced points on the sporangial outline and left the outline opened by deleting one point at the insertion site of sporangiophore.

Landmark based analysis using relative warps and thin plate deformation grids. Relative Warp Analysis of landmarks was performed in PAST and tpsRelw, version

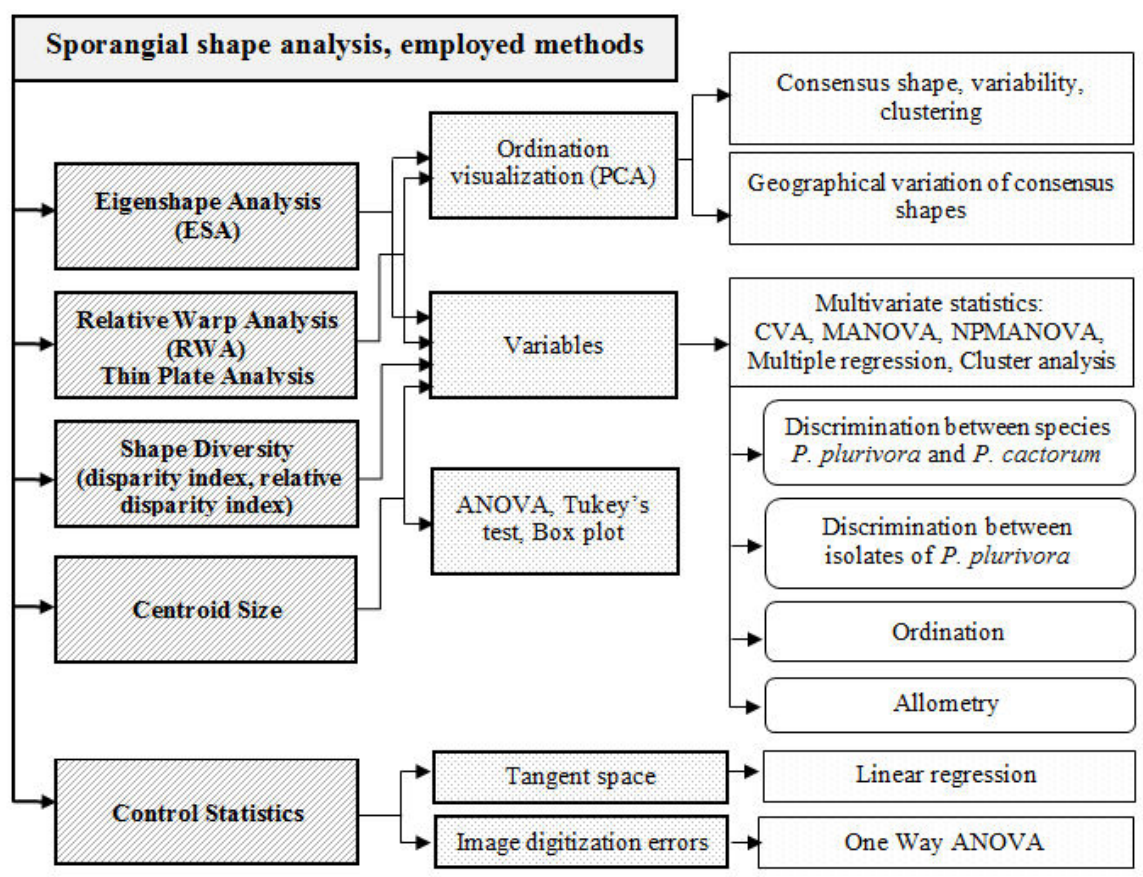

Figure 2 Graphical display of the employed sporangial shape analyses and statistics 
1.53 (Rohlf 2013). Curves were transformed in a series of landmarks using tpsUtil version 1.58 software (Rohlf 2013). Procrustes alignment (Rohlf \& Slice 1990, Dryden \& Mardia 1998) was used in order to remove the differences due to rotation, scale and orientation. The transformed data were then subjected to relative warps analysis (RWA) using thin plate splines TPS (transformation grids) to visualize the shape deformation of each specimen with respect to consensus shape. The alpha scale parameter was set to 0 to equally weight variations at scales of local deformations (Rohlf et al. 1996).

The resulting scores defined the point of tangency between non-euclidean shape space and Euclidian tangent space permitting the subsequent statistical analyses (Bookstein 1989). The employed software PAST implements a system of color coding called Jacobian expansion factors superimposed to deformation grids.

Consensus shape was generated based on covariance matrix of Procrustes aligned coordinates and after generalized least squares adjustment.

Procrustes alignment as well as eigenshape analysis generated a mean shape or consensus shape considered as the best reference shape to which all individual shapes are compared. The reason for using mean shape as reference is because the PCA morphospace which is basically a Kendall space is centered on the mean shape (McLeod 2009).

(b) Centroid size. Common size measure in geometric morphometrics is centroid size computed as the square root of the sum of squared distances of a set of landmarks or semilandmarks from their centroid. The centroid is considered as a better estimate of size than classical morphometric linear measurement such as length, width etc., being uncorrelated to shape variables. Centroid size was calculated on semilandmarks matrix using the software PAST and Tukey's multiple comparisons was applied in order to test for size differ- ences across the samples.

(c) Multivariate statistics. Eigenshape scores (ES scores), relative warps scores (RW scores) and centroid size were combined to be used in Canonical Variate Analysis (CVA), MANOVA and Discriminant Analysis in order to separate species (P. plurivora and $P$. cactorum) and isolates of $P$. plurivora. Shape variance was partitioned into between and within components variation on ES scores, RW scores and centroid size, an approach devised by Magrini and Scoppola (2010) for better discrimination and separation of shapes.

To perform CVA were employed the first 8 ES axes and 8 RW axes considered significant for shape description as established by Jolliffe's cut level (Jolliffe 1986) and the normalized centroid size.

MANOVA is generally the first choice in morphometric studies but there frequent doubts on the correctness of the approach due to the fact that there is a mismatch between number of employed variables and degrees of freedom when using semilandmarks (Webster \& Sheets 2010). Therefore we employed also NPMANOVA on combined data using as distance measure, Mahalanobis distance.

The ordination using Ward clustering algorithm applied to squared Mahalanobis distances was performed to obtain a visual display of distances separating different populations of P. plurivora within the tangent shape space, in the form of a phenogram.

PCA ordination on consensus shapes and overall consensus shape of $P$. plurivora (relative warp scores) was performed in order to compare the mean shapes of different provenances. To illustrate better the closeness between consensus shapes from different locations, a phenogram using Ward algorithm was constructed.

Multiple regression of centroid size on the first 8 RWA axes scores and separately on 8 ES axes scores was performed in order to test for allometric relationship between shape and dimension (Drake \& Klingenberg 2010) as form, 
the space created by shape variables together with dimensional variables displays a particular pattern in terms of variability (Klingenberg 1998, Viscosi \& Cardini 2011). Multiple linear regressions were performed in package stats included in $\mathrm{R}$ version 3.02 ( $\mathrm{R}$ development core team, 2013).

(d) Disparity analysis. Disparity (MD) is a metric devised to measure the amount of morphological diversity within a taxon or within/among populations (Foote 1993, 1994). It assesses how a group of organisms occupy a morphospace, the multidimensional (in Riemmanian sense) space that encompasses the morphological variation within and between taxa. The mean paired dissimilarity among species is a measure of disparity that is intuitively reasonable and unbiased by sample size (Cherry et al. 1982, Foote 1994). MD is measuring the volume of the morphospace occupied by the members of the targeted group: it was calculated for all specimens merged. Large MD values correspond to large dissimilarities in shapes across specimens. The index is standardized for size. Relative disparity was calculated for each location by dividing group disparity to overall disparity. Relative disparity values close to 0.0 indicate that the group contains only a small proportion of the total variation and therefore the overlap in morphospace occupation is small whereas values close to 1.0 indicate extensive morphological overlap (Wilson et al. 2013). We performed the disparity measurement over ESA scores from the first $8 \mathrm{ES}$ axes cumulating $87 \%$ of total variance, for all samples and separately, per locations. For disparity index calculation, the routine Geiger in R was employed (Harmon et al. 2008).

(e) Control statistics. Tangent space. Landmark methods are based on multidimensional Kendall's shape space where shapes are plotted as points which is characterized by its non-Euclidean nature (Mitteroecker \& Huttegger 2009). The point of tangency between nonlinear shape space and the approximated linear tangent is generally, the consensus shape.

tpsSmall software, version 1.29 (Rohlf 2014) was employed to assess the accuracy of shape space by the tangent space. The employed algorithm measures the accuracy of correlation between Euclidean distances in tangent space and Procrustes distances in Kendall's shape space. The projection into the tangent space is performed because standard statistical methods require data being in Euclidian space. Procrustes shape space is curved and must be approximated by the tangent Euclidian space, with the point of tangency between the two spaces being the mean or consensus shape (Viscosi \& Cardini 2011).

Imaging error. The accuracy of image capture and digitization was estimated using the centroid size of 30 sporangia in triplicate. The outlines were traced three times, in different days using same $P$. plurivora subsample of captured images. One way ANOVA on centroids of trice sampled sporangia was calculated to assess the accuracy of imaging the sporangia and outline tracing.

\section{Results}

Shape analysis. Sporangia of $P$. plurivora were described as non-caducous, semipapillate, less frequently bi or pluripapillate characterized by large variation ranging from ovoid or limoniform to ellipsoid with many sporangia displaying abnormal shapes - lateral attachment of the sporangiophore, markedly curved apices, widening to the base (Jung \& Burgess 2009).

Given such a high variability, shape summary depicted by the mean shape is important for species characterization emphasizing a latent property generally blurred by high shape variability.

Eigenshape analysis. yielded 30 axes of which were retained 8 considered significant according to Jolliffe's cut level (cumulating $87 \%$ of total variance). ES1 and ES2 summa- 
rized $66.75 \%$ of the total variance.

ES1 axis, the main variance direction illustrates variations in both length and width of sporangia combined with apical bluntness toward the positive end of the axis and with narrowing of the apical region at the negative end of the axis (Figure 3, Figure 4). ES2 corresponds to variation of sporangia shape from symmetrical mean shape to asymmetrical shape (left asymmetry toward positive end and right asymmetry toward negative end of the axis) with gradual and asymmetric contraction of apical region toward papillate status at both ends of the axis only at opposite directions. ES3 depicts the progressive widening of sporangia which acquire a sub-spherical shape combined with apical bluntness toward the positive end of the axis and progressive narrowing of the apical half of sporangia combined with papillate appearance toward negative end of the axis (Figure 3, Figure 4). ES1 illustrates overall shape modifications while ES2 and
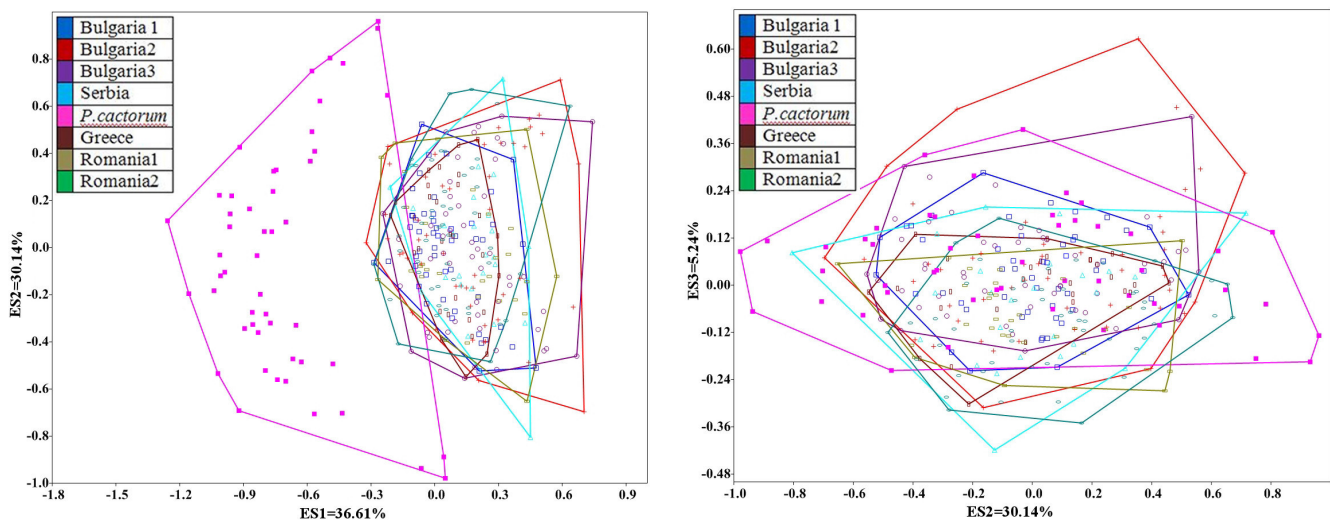

Figure 3 Eigenshape axes $1+2$ and $2+3$. Convex hull interpretation: the vertices of the resulted polygon contain the most extreme shapes positioned relatively to principal axes and set a boundary to the area occupied by shape scores

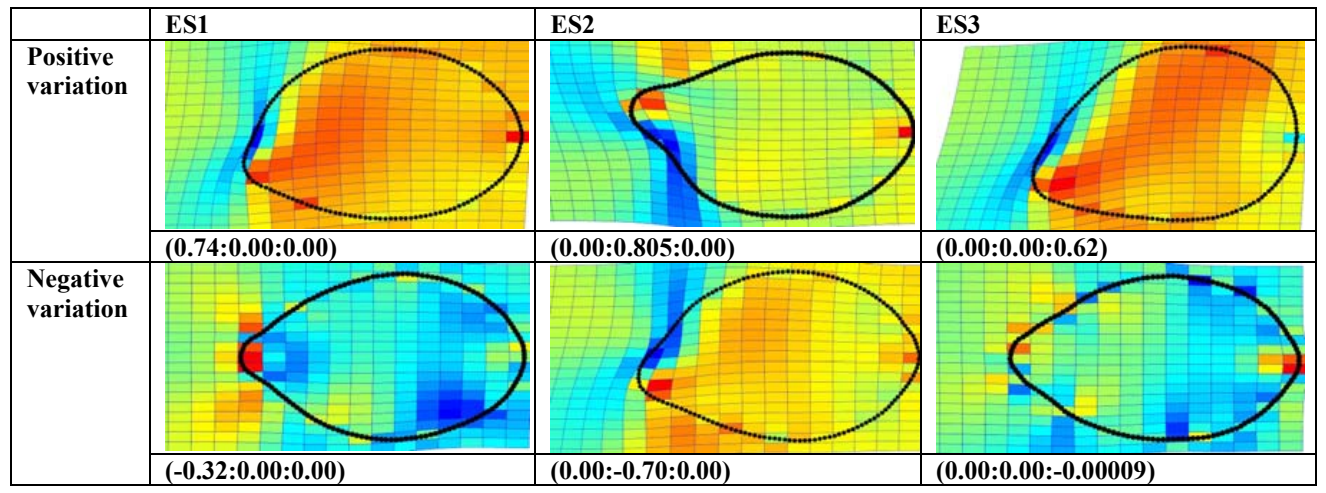

Figure 4 Sporangia shape variation along the 3 first eigenshape axes (thin plate spines deformation grids). In brackets, the coordinates according to each principal axis. Jacobian expansion factors color code: light to dark blue indicating contraction and yellow, orange to red indicating expansion 
ES3 show more local deformations. In order to make easier the interpretation of shape overlap and separation across $P$. plurivora isolates and between P. plurivora and P. cactorum the corresponding areas were generated as convex hulls. Extreme shapes were placed at the vertices of the convex hull for each location. The clear separation between species was obtained on ES1 axis while P. plurivora isolates showed a marked shape overlap on all considered ES axes (Figure 3).

Relative warp analysis yielded 292 relative warp axes of which, for further analysis only 8 were retained (according to cumulative variance they explained $95.48 \%$, corresponding to Jolliffe's cut, at alpha $=0$ ).

Shape separation between $P$. plurivora and P. cactorum did not appear on the first two RW axes summarizing $61.74 \%$ of variability but the separation was produced on RW3 (Figure 5) suggesting that the weight of the papilla as morphological discrimination element is smaller than that of the overall shape. RW1 axis encompassing the greatest shape variability places at the extremes sporangia with rounded lower half and slightly asymmetric apical area corresponding to Bulgaria2, Romania1 and Serbia isolates of P. plurivora. RW2 axis polarizes symmetrical shapes with con- tracted apical half of sporangia corresponding to Greek and Serbian samples. RW3 axis ordinates as extreme shapes with apical asymmetric expansions (negative end of the axis) or symmetric contractions (positive end of the axis) corresponding to Bulgaria2, Romania1 and $P$. cactorum (contractions in apical area indicate the elongation of a papilla) (Figure 6).

At large, the ordinations performed on outline coordinates are similar to those performed on aligned landmark coordinates. However, a better shape separation was obtained through outline analysis.

CVA-MANOVA and Discriminant analysis of $P$. plurivora and $P$. cactorum sporangia. Canonical Variate Analysis of geometric combined data produced a clear separation between $P$. plurivora group and $P$. cactorum (Figure 7, 8). CVA applied separately on ESA and RWA (not shown) scores indicated same separation therefore, one may consider that there is a strong and significant signal of shape separation among species and also among geographical provenances.

The comparison of shapes as analyzed by combined variables resulted in very significant differences between the two species shapes of sporangia (Wilk's lambda $=0.051$ at $\mathrm{F}_{(98: 2001)}=$ 12.26, $P<0.0001)$. Outliers can be observed
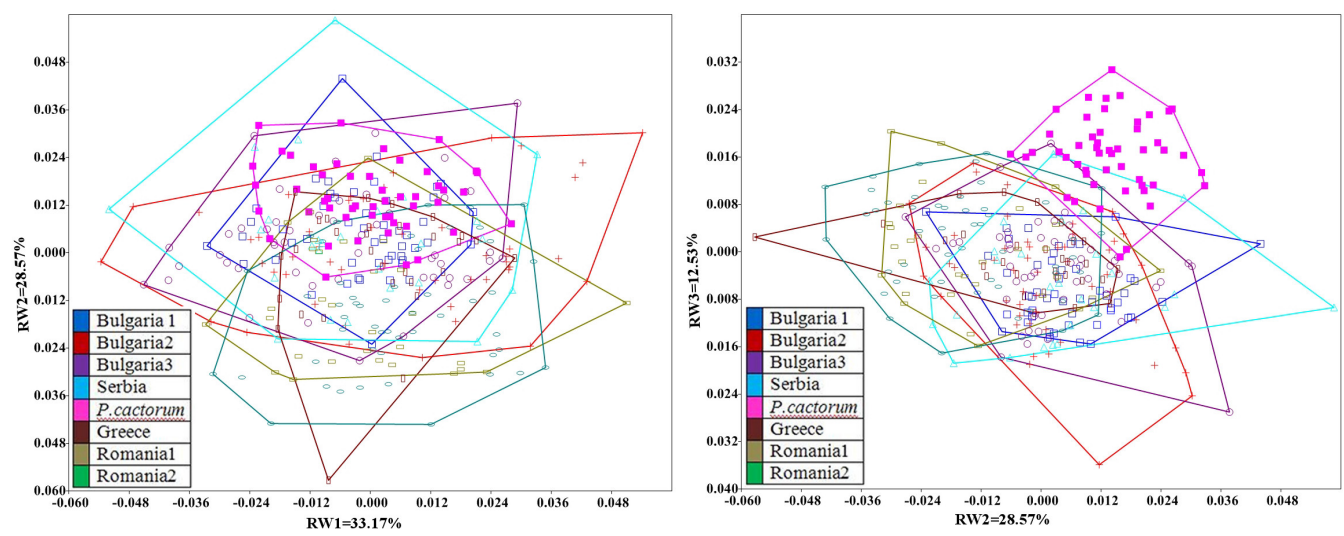

Figure 5 Relative warp ordination. Shape variation represented by relative warp axes $1+2$ and $2+3$. Extreme shapes are vertices of sample convex hulls 
and the less overlapping ellipses of Romania1 isolates and Serbian isolates. Confusion matrix indicated that on average, misclassified sporangia were $20 \%$, with misclassified $P$. cactorum of only $4 \%$.

NPMANOVA using Mahalanobis distance yielded also significant differences across populations of $P$. plurivora and between $P$. cactorum and $P$. plurivora. Permutation test was employed and the result with Bonferoni corrected probabilities yielded $\mathrm{F}=6.61$ at $p<$ 0.0001 . Yet, NPMANOVA probability matrix (not shown) is less informative than MANOVA corresponding matrix. The bottom line is the strong signal indicating shape variability detected by both statistical approaches.

Discriminant analysis (Figure 7) indicated the separation between P. plurivora and P. cac-

\begin{tabular}{|c|c|c|c|}
\hline & RW1 & RW2 & RW3 \\
\hline \multirow[t]{2}{*}{$\begin{array}{l}\text { Positive } \\
\text { variation }\end{array}$} & & & \\
\hline & (0.054:0.00:0.00) & $(0.00: 0.28: 0.00)$ & $\begin{array}{l}(0.00: 0.00: 0.20) \\
\end{array}$ \\
\hline \multirow[t]{2}{*}{$\begin{array}{l}\text { Negative } \\
\text { variation }\end{array}$} & & & \\
\hline & $(-0.054: 0.00: 0.00)$ & (0.00:-0.057:0.00) & (0.00:0.00:-0.035) \\
\hline
\end{tabular}

Figure 6 Extreme shapes on RW1, RW2, RW3 of P. plurivora sporangia (TPS deformation grids). In brackets, RW scores coordinates. Jakobian color code

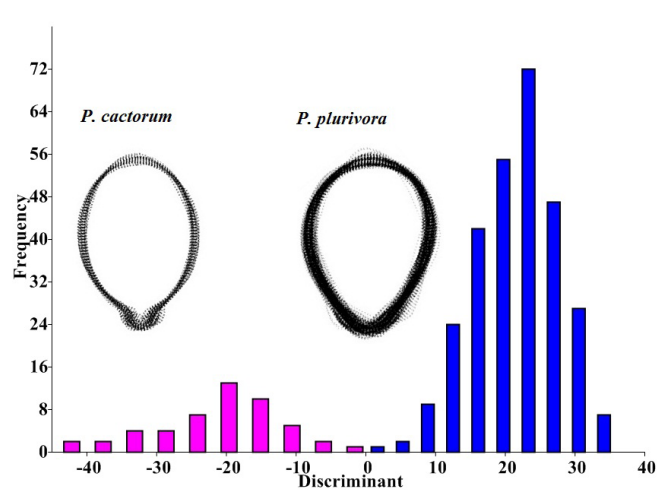

Figure 7 Separation of shapes $P$. plurivora (blue bars) and P. cactorum (pink bars) as result of discriminant analysis. Consensus shapes of the two species with displacement vectors inserted (on the right)

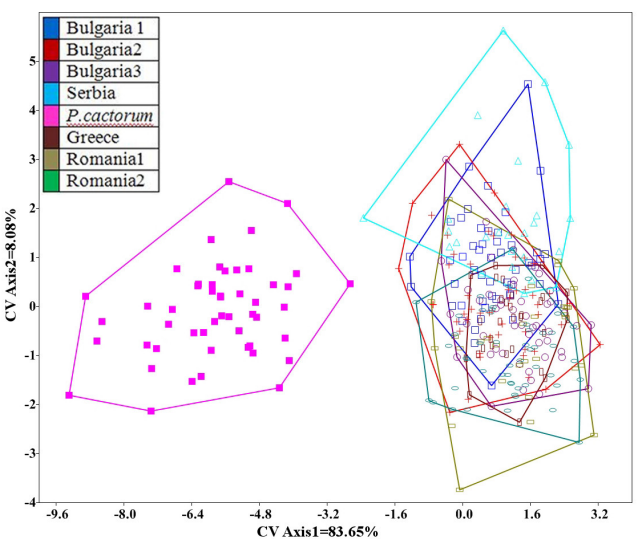

Figure 8 CVA scatter with convex hulls using combined variables: ESA scores, RW scores and centroid size of P. plurivora and $P$. cactorum 
torum (Hotelling's $\mathrm{t}_{2}=1904.6, \mathrm{~F}=130$ at $p<$ 0.0001 ), showing variability among $P$. plurivo$r a$ isolates. Displacement vectors illustrate that most variable regions for the two species are the apex of the sporangium and the basal region where is placed the insertion of the sporangiophore, the only shape details which can be assimilated with landmarks.

MANOVA indicated that greatest dissimilarity in terms of squared Mahalanobis distance was between $P$. cactorum and $P$. plurivora (Figure 8). The phenogram generated on distance data indicates that Serbian samples are clustering together with the rest of isolates from other locations, yet on a different, more distant branch (Figure 9). Bulgarian isolates from Velingrad clustered together with Greek isolates while Romanian isolates clustered together. The other two Bulgarian (Tran and Tulovo) locations show close distance among shapes.

Multiple regression of RW scores on centroid size yielded an adjusted multiple coefficient of determination of 0.19 with significant correlations of centroid size on RW3 and RW8 axes $(p<0.0001)$ and not significant

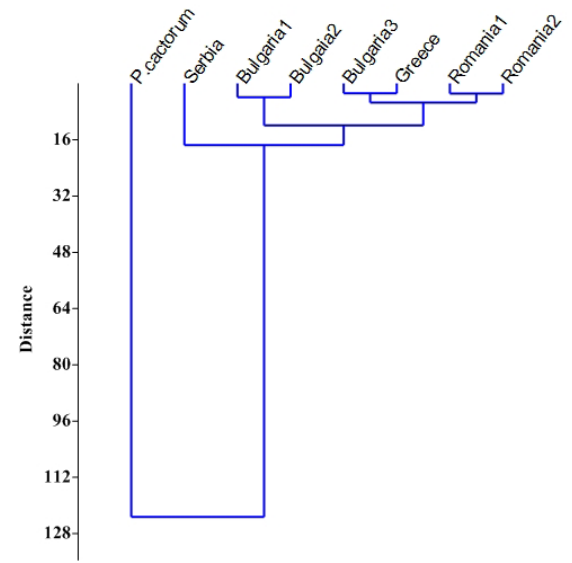

Figure 9 Clustering of sporangia shapes across locations, combined variables (clustering algorithm - Ward, cophenetic correlation $=0.94$ similarity measure - squared Mahalanobis (on the left) results in the case of correlations between centroid size and other RW axes. ANOVA output indicated significant result of the regression $\left(\mathrm{F}_{(8,327)}=11.25\right.$ at $\left.p<0.0001\right)$. However, this result indicates a modest and probably unimportant allometry between size and shape. Same analysis performed on ES scores of the first 8 principal axes regressed on centroid size yielded a weak multiple correlation (multiple $R^{2}=0.19$ at $\left.\mathrm{F}_{(6,329)}=14.9, p<0.0001\right)$ confirming the obtained result when RW scores were employed as dependent variables. Highly significant correlations were obtained for ES1 and ES2, significant for ES3 and marginally significant for ES4.

PCA ordination of local P. plurivora consensus shapes using relative warp scores. The ordination performed on RW scores collected from consensus shape (local and overall $P$. plurivora mean shape) indicates a clear segregation of Serbian, Greek and Bulgarian2 consensus shapes in the lower right area of centered PC axes (Figure 10). Romanian2 and Bulgarian3 consensus shapes are separated in the upper right quadrant of the ordination axes 1 and 2 while Romanian1

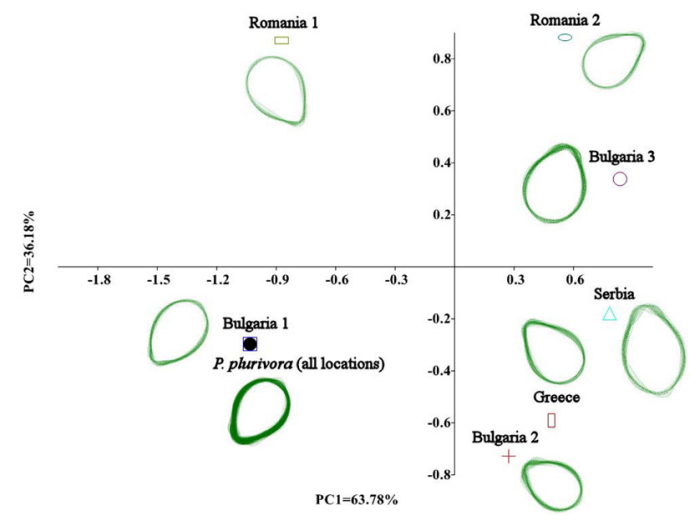

Figure 10 PCA ordination of consensus local and overall P. plurivora shapes using relative warp scores. Local consensus shapes included together with overall main shape on the extreme left of the graphical representation 
consensus shape is quite distant from all other mean shapes. Interestingly, Bulgarian1 mean shape overlaps the general mean shape, apparently the closest mean shape to the general reference in P. plurivora morphospace.

The corresponding phenogram (Figure 11) is illustrating heuristically the similarities in mean shapes of different geographical provenances in the same way PC ordination depicted their placement in the morphospace. Using for comparisons only local mean shapes, a great amount of variability inducing noise being avoided, the differences in isolates become more obvious and those can be discriminated more easily.

Isolates corresponding to Romanial and Bulgarial were clustering together with the overall consensus shape while Bulgaria2 and Greece clustered separately. A third cluster merged Serbian, Bulgarian3 and Romanian2 isolates. This pattern is different from the pattern generated on combined variables of all sporangia (see for comparison Figure 8) characterized by different assignment of isolates to clusters. The influence of centroid size differences and asymmetry (which is excluded from the mean shape as shape characteristic)

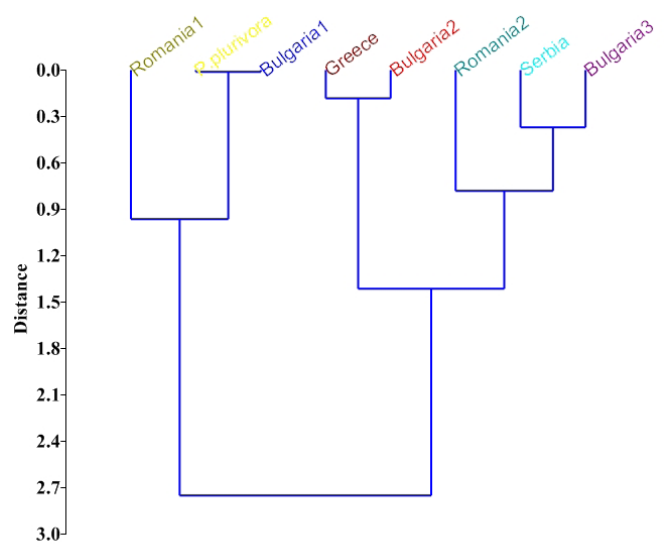

Figure 11 Phenogram depicting the distances across consensus shapes of $P$. plurivora, overall mean shape and local mean shapes (Ward algorithm, Euclidean distance) was expressed as different clustering pattern. The same situation was encountered by other researchers the different clustering pattern depending on whether combined size and shape or only shape variables were employed (Neustupa \& Št'asný 2006).

Centroid size. One way ANOVA performed on centroid size of $P$. plurivora samples resulted in overall significant differences across locations $\left(\mathrm{F}_{(7,184)}=33.76, P>0.0001\right)$. Tukey's pairwise comparisons however, indicated significant size differences across provenances: highly different centroid size of Romania 2 compared to all other isolates, and also high differences in centroid size between Serbian isolates, Greek and Romanian2 isolates, at $p<0.00001$. The other pairwise comparison resulted in non-significant differences.

The differences were highly significant between Serbian isolates and the rest of isolates. Bulgarian isolates were highly similar among them. The mean of Romanian1 isolates was not significantly different from Bulgarian isolates while Romanian2 isolates were extremely significant in terms of mean differences compared to other isolates. The position of median in this graphical representation provides a visual confirmation of size variation across the samples: $P$. cactorum median is close to Serbian isolates of $P$. plurivora in terms of centroid size.

Box-plot representation of centroid size (Figure 12) indicated that the greatest dimensional variation characterized Romanian2 isolates concerning mostly the large sized, over median value of other isolates, sporangia. The smallest variation in $P$. plurivora sporangia indicated Bulgarian isolates while P. cactorum showed largest dimensional variation. High dimensional variation corroborates with shape variation spanning from symmetrical consensus shape to conspicuously asymmetric shapes.

Disparity analysis. The positioning of different isolates in the shape space of $P$. plurivora is better understood having a numerical tag such as the morphological dispar- 
ity index. Overall disparity calculated on ES scores of all sporangia was relatively high (0.651) giving a numerical representation of the extent of the occupied morphospace (Figure 13). Compared to this value, the relative disparities in isolates showed different levels of heterogeneity in terms of shapes: Bulgarian isolates 2 and 3 appeared to be most diversified while less diversified shapes were recorded for Greek and Bulgarian1 isolates (according to

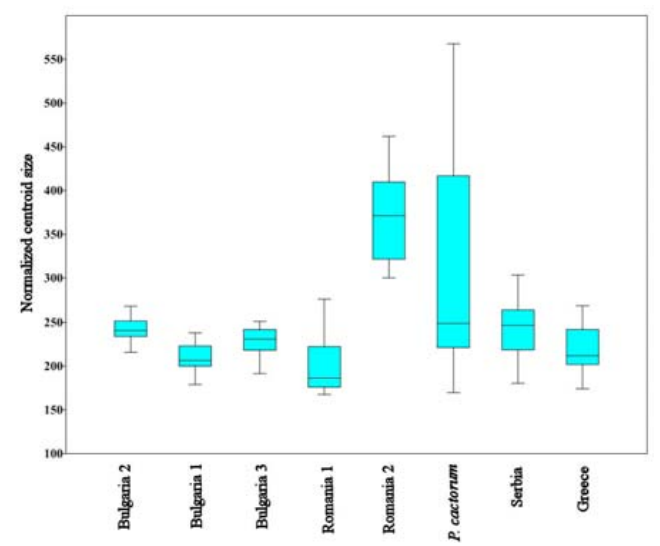

Figure 12 Box plot representation of centroid size in P. plurivora and P. cactorum: median, $25-75 \%$ quartiles, minimum and maximum

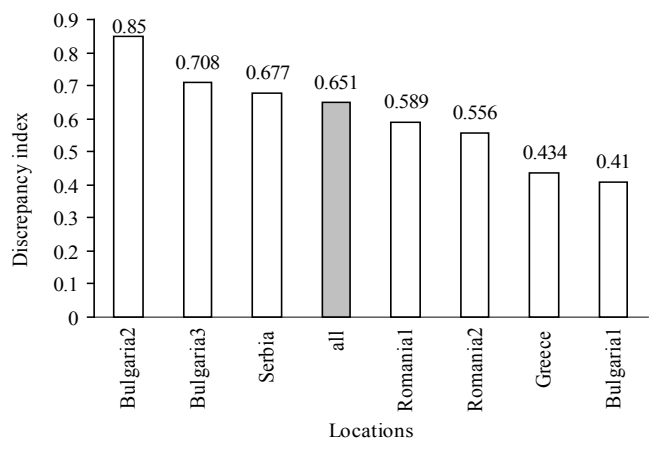

Figure 13 Relative disparity contrasted to overall disparity (in red) in sporangial shape in P. plurivora

lower overlap with overall disparity). Comparing the convex hull encompassing Bulgaria2 and 3 eigenshapes which occupy extended 288 areas (Figure 3 ) with values of relative morphological disparity index, one can have the confirmation of high shape variation/diversity characterizing these locations. Close to overall disparity and accordingly, to morphological diversity were Romanian and Serbian isolates.

Tangent space the regression through the origin of a set of Euclidean distances in the Euclidean space onto the set of Procrustes shape distances yielded a perfect correlation between the two types of distances $(r>0.99)$ showing that shape variation in data set is small enough to validate multivariate statistical analyses.

Imaging error. Centroid size was calculated for imaging error using three different digitizations of the same 30 sporangia ( $P$. plurivora - Tran sample). One way ANOVA resulted in non-significant differences across the repetitions $\left(\mathrm{F}_{(2 ; 87)}=0.20, p=0.81\right)$, bootstrapped standard error of 5.84E-06 indicating small differences due to digitization of captured images.

\section{Discussion}

Geometric morphometric analysis of $P$. plurivora with respect to species discrimination as compared to $P$. cactorum and the variability of its isolates indicated that this approach produced reliable information backed up by significant statistical results. Recent studies developed at molecular level showed that $P$. plurivora exhibits high polymorphism and is structured in four divergent microsatellite clusters, with unclear geographic pattern (Schoebel et al. 2014). One of previous observations on high dimensional variability of sporangia within same species of Phytophthora (Brasier 1991) was confirmed by our observations which were analyzed quantitatively to produce additional information on the extent of variability but also gave a model of the sporangial fundamental shape characterizing $P$. plurivora. Landmark based morphometric analysis captured overall shape differences and spread the variation across the whole spec- 
imen. Alternatively, outline analysis permitted a better separation of shapes since it is based on curvature characteristics.

Shape analysis produced a clear discrimination at species level between $P$. plurivora and $P$. cactorum at consensus shape level and permitted the quantitative assessment of amongisolates variation (see discriminant analysis results). The variation of sporangial shapes across isolates of $P$. plurivora spread over rather large regional area (South -Eastern Europe) apparently confirmed other similar studies on different types of objects such as leaves (Viscosi et al. 2009) or vole dentition (McGuire 2010) but the major factors contributing to variability (site characteristics, hosts or geographic origin) remain to be revealed in future studies.

Shape ordination of isolates produced a pattern of dissimilarities at smaller local scale (Bulgarian isolates expressed significant shape and also size differences) and larger geographic area (differences among Bulgarian, Greek, Serbian and Romanian isolates). The analysis showed that the most variable areas of the sporangia, either semipapillate or papillate were the base and the apical region. However, shape variability spanned a rather restricted range permitting the projection in tangent space, hence validating further statistical analyses.

Outline and landmark based morphometric methods permitted species discrimination (comparisons between $P$. cactorum and $P$. plurivora) at higher quantitative resolution than classical morphological assessments, comparable to molecular methods. More than half of the shape variation was accounted for the first 2 ES axes $(66.75 \%)$ and first two RW axes $(61.74 \%)$. ESA performed better in terms of species shape (P. plurivora and P. cactorum) separation which was achieved on the first two axes while RWA produced a clear species shape separation on RW 3 axis (Figure 3 and 5).

The mean or consensus shape proved to be a better shape descriptor than classical mor- phological descriptors being an important species and isolates' level parameter: it is the only shape that minimizes the overall deviation of landmarks or curves one from another and it provides the greatest overall similarity with all other shapes across a sample (McLeod 2010). Bulgarian isolates from Tulovo and Velingrad, Greek isolates, Romanian isolates from ClujNapoca and Serbian isolates occupied close positions in the morphospace as PCA ordination indicated (especially PC1 axis). Bulgarian isolates from Tran were almost coincidental to overall mean shape. The combination of shape variables and size variables referred as form variables produced an ordination (clustering) characterized by the different assignment of isolates to clusters as compared to ordination performed on mean shapes. These differences could be considered noise produced by centroid size variation and asymmetry of sporangia. Although the average shape of $P$. plurivora sporangia is radially symmetrical, a gradient of asymmetrical forms has resulted from shape analysis. Frequent asymmetrical sporangia were reported as a constant and distinctive character in several Phytophthora species (P. kernoviae, P. cinnamomi, P. morindae, P. mengei, $P$. glovera) including $P$. plurivora and in a broader sense $P$. citricola group (Hüberli 1995, Jung \& Burgess 2009, Hong et al. 2009, Abad et al. 2011). Symmetry represents an idealized a priori phenotype (Freeman et al. 2005) therefore; the asymmetry affecting a large proportion of sporangia is probably reflecting developmental stress and lower fitness to environmental pressure (Mather 1953, van Valen 1962, Graham \& Felley 1985, Polak 2003, Graham et al. 2010). This kind of large individual variation plasticity characterizing the $P$. plurivora sporangia was observed in other types of organisms too, such as oak leaves (Viscosi et al 2009, Viscosi \& Cardini 2011). However, symmetrical structures are favored over asymmetrical in most of organisms displaying symmetry because this creates a class of patterns which are energetically 
more economic and a particular symmetrical shape of sporangia is generally favored over other observed shapes (Mbaka et al. 2010). Shape variation which is pronounced in Phytophthora species can be induced by several environmental factors (Zentmeyer \& Ribeiro 1977, Alizadeh \& Tsao 1985), but it is also genetically determined (Schoebel et al. 2014). The question whether asymmetry in sporangia notified as a major variability factor both in outline and landmark analyses reflects developmental instability or is the consequence of microhabitat variability is still unclear and worth further studies.

Centroid size demonstrated to be a better size descriptor than classical linear measurements. It displayed a weak correlation with shape variables suggesting a weak allometry in the case of $P$. plurivora (multiple $R^{2}=0.19$ ). This descriptor also permitted a better assessment of variability across isolates in conjunction with shape. Bulgarian isolates displayed remarkable size homogeneity being close to Greek, Romanian1 and Serbian isolates but highly and significantly different from Romania2 isolates which appeared to be the most variable in terms of centroid size. However, largest dimensional variation was observed in P. cactorum.

The morphological diversity assessed by means of the metric provided by disparity index was spanning the morphospace of $P$. plurivora, a space centered on the consensus shape, characterizing the local isolates. Most diverse shapes occupying a large extent of the morphospace appeared to be isolates from two Bulgarian locations while more homogenous in terms of shapes appeared to be isolates from Greece and one from Bulgaria. Romanian and Serbian isolates displayed intermediate shape diversity.

Based on geometric morphometric and multivariate statistics results, the question whether sporangial shape can be used a discriminant character in species identification was answered: mean or reference shape was more reliable than an array of shapes covering the large variability defining this species. There is a marked variability among isolates affecting shape and dimensions of sporangia considering the large environmental envelope covering several climatically distinct areas in South-East Europe, the species diversity and geographic populations of woody hosts.

One can only speculate that these recent lineages are still unstable morphologically therefore, asymmetry, shape deformations and dimensional variability represent the morphological hallmark of the group. Mean shape however, is a species parameter defining the species morphospace which is characteristic in a comparable way to molecular markers. Our results are placed in the larger context in which it is largely recognized that geometric morphometric approach has marked fundamental advances over traditional approaches in species morphology used for group discrimination and inferences of evolutionary or ecological importance (Rohlf \& Corti 2000, Shipunov \& Bateman 2005, Mitteroecker \& Gunz 2009, Mitteroecker et al. 2013).

\section{Acknowledgements}

The present work was developed in the frame of SEE-ERA.NET.Plus project ERA-138: Diversity of invading Phytophthora spp. plant pathogens in agro and forest ecosystems in Southeast Europe. We express our gratitude for the valuable help provided by dr. Vladan Ivetic in Serbia and dr. Chariklea Perlerou in Greece in terms of laboratory work, identifications and advice. We also express our gratitude dr. Dănuţ Chira for providing the soil samples from location Caşin (Romania1).

\section{References}

Abad G., Ivors K.L., Gallup A.A., Abad J.A., Shew D., 2011. Morphological and molecular characterization of Phytophthora glovera sp. nov. from tobacco in Brasil. 
Mycologia 103(2): 311-350. DOI: 10.3852/09-157.

Alizadeh A., Tsao P.H., 1985. Effect of light on sporangium formation, morphology, ontogeny and caducity of Phytophthora capsici and Phytophthora palmivora MF4 isolates from black pepper and other hosts. Transactions of the British Mycological Society Journal 85(1): 4769. DOI: $10.1016 / \mathrm{S} 0007-1536(85) 80155-8$.

Beakes G.W., Honda D., Thines M., 2014. Systematics of the Straminipila: Labyrintholomycota, Hyphochytridiomycota and Oomycota. In Esser, K 9ed. Series) The Mycota: a comprehensive treatise of fungi as experimental systems for basic and applied research. McLaughlin, D.J., Spatafora, J.W., (vol. eds.). Systematics and Evolution. Part A, VII. IInded. Springer, Heidelberg, Berlin, pp. 30-97.

Bookstein F.L., 1989. Principal warps: thin plate splines and the decomposition of deformations. IEEE Transactions on Pattern Analysis and Machine Intelligence 11: 567-585. DOI: 10.1109/34.24792.

Brasier C.M., 1991. Current questions in Phytophthora systematics: the role of population approach. In: Lucas, J.A., Shalttock, R.C., Shaw, D.S., Cooke, L.R. (eds.). Phytophthora: Symposium of the British Mycological Society. Press Syndicate of the Cambridge University, Cambridge, U.K., pp. 103-128.

Brasier C.M., 1996. Phytophthora cinnamomi and oak decline in Southern Europe. Environmental constraints including climate change. Annales de Sciences Forestières 53(2-3): 347-358. DOI: 10.1051/forest:19960217.

Cech T.L., 1998. Phytophthora decline of alder (Alnus spp.) in Europe. Journal of Arboriculture 24(6): 339343.

Cherry L.M., Case S.M., Kunkel J.G., Wyles J.S., Wilson A.C., 1982. Body shape metrics and organismal evolution. Evolution 36: 914-933. DOI: 10.2307/2408072.

Dick M.W., 2001. Straminipilous fungi: systematics of Peronosporomycetes including accounts of the marine straminipilous Protists, the Plasmodiophorids and similar organisms, pp. 660. DOI: 10.1007/978-94-0159733-3

Drake A.G., Klingenberg C.P., 2010. Large scale diversification of skull in domestic dogs: disparity and modularity. American Naturalist 175: 287-301. DOI: 10.1086/650372.

Dryden N.I.L., Mardia K.V., 1998. Statistical shape analysis. J. W. Wiley, New York, 376 p.

Erwin D.C., Ribeiro O.K., 1996. Phytophthora diseases worldwide. APS Press. American Phytopathological Society, St. Paul, Minnesota.

Foote M., 1993. Contribution of individual taxa to overall morphological disparity. Paleobiology 19: 403-419.

Foote M., 1994. Morphological disparity in OrdovicianDevonian crinoids and the early saturation of morphological space. Paleobiology 20(3): 320-344.

Francoy T.M., de Faria Franco F., Roubik D.W., 2012. Integrated landmark and outline-based morphometric methods efficiently distinguish species of Euglossa (Hymenoptera: Apidae: Euglossini). Apidologie 43:
609-617. DOI: 10.1007/s13592-012-0132-2.

Freeman D.C., Brown M.L., Duda J.J., Graraham J.H., Emden J.M., Krzysik J.A., Balbach H., Kovacic D.H., Zak J. C., 2005. Leaf fluctuating asymmetry, soil disturbance and plant stress: a multiple year comparison using two herbs, Ipomoea pandurata and Cnidoscolus stimularis. Ecological Indicators 5(2): 85-95. DOI: 10.1016/j.ecolind.2004.05.002.

Gallegly M.E., Hong, C., 2008. Phytophthora: Identifying species by morphology and DNA fingerprints. American Phytopathological Society, St. Paul, Minnesota.

Goodwin S.B., 1997. The population genetics of Phytophthora. Phytopatothology 87(4): 462-473. DOI: 10.1094/ PHYTO.1997.87.4.462.

Graham J.H., Felley J.D., 1985. Genomic coadaptation and developmental stability within introgressed populations of Enneacanthus gloriosus and E. obesus (Pisces, Centrarchidae). Evolution 39: 104-114. DOI: $10.2307 / 2408520$.

Graham J.H., Raz S., Hel-Or H., Nevo E., 2010. Fluctuating asymmetry: methods theory, and applications. Symmetry 2: 466-540. DOI: 10.3390/sym2020466.

Hammer, Ø. Harper, D.T., Ryan, P.D., 2001. PAST: paleontological statistics software package for education and data analysis. Paleontologia Electronica. Web: http://palaeo-electronica.org. Accesed: 04.2015.

Hansen E., Delatour C., 1999. Phytophthora species in oak forests of North-East France. Annales des Sciences Forestières 56: 539-547. DOI: 10.1051/forest:19990702.

Harmon L.J, Jason T.W., Chad D.B., Richard E.G., Wendell C., 2008. GEIGER: investigating evolutionary radiations. Bioinformatics 24:129-131. DOI: 10.1093/ bioinformatics/btm538.

Hong C.X., Gallegly M.E., Browne G.T., Bhat R.G., Richardson P.A., Kong P., 2009. The avocado subgroup of Phytophthora citricola constitutes a distinct species, Phytophthora mengei sp. Nov. Mycology 101(6): 833840. DOI: $10.3852 / 08-214$.

Hüberli D., 1995. Analysis of variability among isolates in Phytophthora cinnamomi Rands. From Eucalyptus marginata Donn. Ex Sm. and E. calophylla R.Br. based on cultural characteristics, sporangia and gametangia morphology and pathogenicity. Thesis for B.S. Scholl of Biological and Environmental Sciences, Murdoch University.

Jeffers S.N., Martin S.B., 1986. Comparison of two media selective for Phytophthora and Pythium species. Plant Disease 70:1036-1043. DOI: 10.1094/PD-70-1038.

Jeger M.J., Pautasso M., 2008. Comparative epidemiology of zoosporic plant pathogens. European Journal of Forest Pathology 122: 111-126. DOI: 10.1007/s10658008-9289-y.

Jensen R.J., Ciofani K.M., Miramontes L.C., 2002. Lines, outlines, and landmarks: morphometric analyses of leaves of Acer rubrum, Acer saccharinum (Aceraceae) and their hybrid. Taxon 51: 475-492. DOI: $10.2307 / 1554860$.

Jolliffe I.T., 1986. Principal Component Analysis. Spring- 
er, New York. DOI: 10.1007/978-1-4757-1904-8.

Jönsson U., Lundberg L., Sonesson K., Jung T., 2003. First record of soilborne Phytophthora species in Swedish oak forests. Forest Pathology 33: 175-179. DOI: 10.1046/j.1439-0329.2003.00320.x.

Jung T., Blaschke H., Neumann P., 1996. Isolation, identification and pathogenicity of Phytophthora species from declining oak stands. European Journal of Forest Pathology 26: 253-272. DOI: 10.1111/j.1439-0329.1996. tb00846.x.

Jung T., Blaschke H., Osswald W., 2000. Involvement of soilborne Phytophthora species in Central European oak decline and the effect of site factors on the disease. Plant Pathology 49: 706-718. DOI: 10.1046/j.13653059.2000.00521.x.

Jung T., Burgess T., 2009. Re-evaluation of Phytophthora citricola isolates from multiple woody hosts in Europe and North America reveals a new species, Phytophthora plurivora sp. nov. Persoonia 22: 95-110. DOI: 10.3767/003158509X442612.

Jung T., Nechwatal J., Cooke D.E.I., Hartman G., Blaschke H., Osswald W.F., Duncan J.M., Delatour C., 2003. Phytophthora pseudosyringae sp. nov., a new species causing rot and collar rot of deciduous tree species in Europe. Mycological Research 107: 772-789. DOI: 10.1017/ S0953756203008074.

Kendall D.G., 1989. A survey of the statistical theory of shape. Statistical Science 4(2): 87-120. DOI: 10.1214/ ss/1177012582.

Klingenberg C.P., 1998. Heterochrony and allometry: the analysis of evolutionary change in ontogeny. Biological Reviews 73: 79-123. DOI: 10.1017/ S000632319800512X.

Kroon P.N.M., Brouwer H., de cock W.A.M., Govers F., 2012. The genus Phytophthora Anno 2012. Phytopathology 102: 348-364. DOI: 10.1094/PHYTO-01-110025 .

Lamour K.H., Win J., Kamoun S., 2007. Minireview Oomycete genomics: new insights and future direction. FEMS Microbiology Letters 274: 1-8. DOI: 10.1111/ j.1574-6968.2007.00786.x.

Lohman G.P., 1983. Eigenshape analysis of microfossils. A morphometric method for describing changes in shape. Mathematical Geology 15: 659-672. DOI: 10.1007/BF01033230.

Lyubenova A., Kostov K., Tsvetkov I., Oszako T., Borys M., Sikora K., Jung T., Slavov S. 2012. Diversity of Phytophthora species in forest ecosystems in Bulgaria'6th International IUFRO Unit 7.02.09 Meeting on 'Phytophthora in Forests and Natural Ecosystems' in Cordoba, Spain.

Lyubenova A., Kostov K., Tsvetkov I., Slavov S., 2014. Possible contribution of Phytophthora spp. in decline of Norway spruce (P. abies (L.) H. Karst.) stands in Vitosha mountain. Silva Balcanica 15(1): 100-109.

Magrini S., Scoppola A., 2010. Geometric morphometrics as a tool to resolve taxonomic problems: the case of Ophioglossum species (ferns). In: Nimis P.L., Vignes lebbe, R. (eds.), Tools for identifying biodiversity: Progress and problems, pp. 251-256.

Mather K., 1953. Genetical control of stability in development. Heredity 7: 297-336. DOI: 10.1038/ hdy. 1953.41.

Mbaka J.N., Losenge T., Waiganjo M.M., Wamocho L.S., 2010. Phenotypic variation of three Phytophthora cinnamomi populations from macadamia growing areas in Kenya. Journal of Animal and Plant Sciences 8(1): 900-911.

McGuire J.L., 2010. Geometric morphometrics of vole (Microtus californicus) dentition as a new paleoclimate proxy: shape change along geographic and climatic clines. Quaternary International 212: 198-205. DOI: 10.1016/j.quaint.2009.09.004.

McKnight T.L., Hess D., 2000. Climate zones and types. Physical geography: a landscape appreciation. Upper Saddle River, N.J., Prentice Hall.

McLeod N., 2009. Shape theory. Paleontological Association Newsletter 71: 34-47.

McLeod N. 2010. Shape models I: the thin plate spline. Paleontological Association Newsletter 73: 24-39.

McLeod N., 2012. Going round the bend: eigenshape analysis I. Paleontological Association Newsletter 80: 35-45.

McLeod N., Rose K.D., 1993. Inferring locomotor behavior in paleogene mammals via eigenshape analysis. American Journal of Science 293A: 300-355. DOI: 10.2475/ ajs.293.A.300.

Milenković I., Keča N., Karadžić D., Nowakowska J.A., Borys M., Sikora K., Oszako T., 2012. Incidence of Phytophthora species in Beech stands in Serbia. Folia Forestalia Polonica, serties A 54(4): 223-232.

Milenković I., Keča N., Letic L., Nicolic V., 2011. Presence of Phytophthora species in the alluvium of Sava river. Book of abstracts XVI Congress of European Mycologists, Halkidiki, Porto Carras, 19-23.09.

Milenković I., Nowakowska J. A., Oszako T., Mladenović K., Lučić A., Rakonjac L., Karadžić D., 2014. Morphological and molecular identification of Phytophthora species from maple trees in Serbia. Genetika 46(2): 353-368. DOI: 10.2298/GENSR1402353M.

Mitteroecker P., Gunz P., 2009. Advances in geometric morphometrics. Evolutionary Biology 36: 235-247. DOI: 10.1007/s11692-009-9055-x.

Mitteroecker P., Gunz P., Windhagen S., Schaefer K., 2013. A brief review of shape, form and allometry in geometric morphometrics, with applications to human facial morphology. Hystrix. The Italian Journal of Mammalogy 24(1): 59-66.

Mitteroecker P., Huttegger S.M., 2009. The concept of morphospaces in evolutionary biology: mathematics and metaphors. Biological Theory 4(1): 54-67. DOI: 10.1162/biot.2009.4.1.54.

Neige P. 2003. Combining disparity with diversity to study the biogeographic pattern of Sepiidae. Berliner Paläobiol. Abh. 3: 189-197.

Neustupa J., Št'astny J., 2006. The geometric morphomet- 
ric study of Central European species of the genus $M i$ crasterias (Zygnematophyceae, Viridiplantae). Preslia 78: 253-263.

Neustupa J., Černá K., Št’astný J., 2009. Diversity and morphological disparity of desmid assemblages in Central European peatlands. Hydrobiologia 630: 243-256. DOI: $10.1007 /$ s10750-009-9799-4.

Nowakowska J.A., Oszako T., Borys M., Sikora K., Kubiak K., Olejarski I., 2012. Genetic variability of Phytophthora community in natural water resources assessed with microsatellite DNA markers. Baltic Forestry 18(1): 56-64.

Oszako T., Orlikowski L.B., 2005. First data on the occurrence of Phytophthora cinnamomi on pedunculated oak in Poland. Sylwan 149(10): 47-53.

Perlerou C., Tziros G., Vettraino A.M., Diamandis S., 2010. Phytophthora cryptogea causing ink disease of Castanea sativa newly reported in Greece. New Disease Reports 20: 31. DOI: 10.1111/j.1365-3059.2010.02268. $\mathrm{x}$.

Polak M., 2003. Developmental instability: causes and consequences. New York, NY, USA: Oxford University Press.

R Core Team, 2013. R: A language and environment for statistical computing. R Foundation for Statistical Computing, Vienna, Austria. Web: http://www.R-project. org/.

Ray T.S., 1992. Landmark eigenshape analysis: homologous contours, leaf shape in Syngonium (Araceae). American Journal of Botany 79: 69-76. DOI: $10.2307 / 2445199$.

Ricklefs R.E., Miles D.B., 1994. Ecological and evolutionary inferences from morphology: An ecological perspective. In: Wainwright P.C., Reilly, S.M. (eds.), Ecological morphology: integrative organismal biology. University of Chicago Press, Chicago, Illinois, U.S.A., pp. 13-41.

Rohlf F.J., 2010. tpsDig, version 2.16. Department of Ecology and Evolution, State University, New York at Stony Brook, New York.

Rohlf F.J., 2013. tpsUtil, version 1.58. and tpsRelw version 1.53. Department of Ecology and Evolution, State University, New York at Stony Brook, New York.

Rohlf F.J., 2014. tpsSmall, version 1.29. Department of Ecology and Evolution, State University, New York and Stony Brook, New York.

Rohlf F.J., Corti M., 2000. Use of two-block partial least squares to study covariation in shape. Systematic Biology 49: 740-753. DOI: 10.1080/106351500750049806.

Rohlf F.J., Loy A., Corti M., 1996. Morphometric analysis of Old World Talpidae (Mammalia, Insectivora) using Partial Warp scores. Systematic Biology 45(3): 344362. DOI: $10.1093 / \mathrm{sysbio/45.3.344.}$

RohlfF.J., Slice D., 1990. Extension of the Procrustes method for the optimal superimposition of landmarks. Systematic Zoology 39: 40-59. DOI: 10.2307/2992207.

Roy K., Balch D.P., Hellberg M.E., 2001. Spatial patterns of morphological diversity across indo-Pacific: analy- ses using strombid gastropods. Proceedings of Royal Society of London B 268: 2503-2508. DOI: 10.1098/ rspb.2000.1428.

Roy K., Foote M., 1997. Morphological approaches to measuring biodiversity. Trends an Ecology and Evolution 12: 277-281. DOI: 10.1016/S0169-5347(97)810269.

Schock F., Perrimon N., 2002. Molecular mechanisms of epithelial morphogenesis. Annual Review of Cell and Developmental Biology 18: 463-493. DOI: 10.1146/annurev.cellbio.18.022602.131838.

Schoebel C.N., Stewart J., Gruenwald N.J., Rigling D., Prospero S., 2014. Population history and pathways of the plant pathogen Phytophthora plurivora. PLoS ONE 9(1): e85368. DOI: 101371/journal.pone.0085368.

Shipunov A.B., Bateman R.M., 2005. Geometric morphometrics as a tool for understanding Dactylorhiza (Orchidaceae) diversity in European Russia. Biological Journal of the Linnean Society 85: 1-12. DOI: 10.1111/ j.1095-8312.2005.00468.x.

Slice D.E., Bookstein F.L., Marcus L.F., Rohlf F.J., 1996. A glossary of morphometrics. In: Marcus L.F., Corti M., Loy A., Naylor G.J.P., Slice D.E. (eds.): Advances in Morphometrics, Plenum Press, New York, pp. 531551.

Szabo I., Lakatos F., Sipos G., 2013. Occurrence of soilborne Phytophthora species in declining broadleaved forests in Hungary. European Journal of Plant Pathology 137: 159-169. DOI: 10.1007/s10658-013-0228-1.

Tziros G., Diamandis S,. 2014. First report of Phytophthora cinnamomi causing ink disease on Castanea sativa in Greece. Journal of Plant Pathology 96(2): doi 10445/IPP.V9612.021.

Van Valen L., 1962. A study of fluctuating asymmetry. Evolution 16: 125-142. DOI: 10.2307/2406192.

Viscosi V., Cardini A., 2011. Leaf morphology, taxonomy and geometric morphometrics: a simplified protocol for beginners. PLoS One 6(10), e25630. DOI: 10.1371/ journal.pone. 0025630 .

Viscosi V., Fortini P., Slice D.E., Loy A., Blasi C., 2009. Geometric morphometric analysis of leaf variation in four oak species of the genus Quercus (Fagaceae). Plant Biosystems 143(3): 575-587. DOI: 10.1080/11263500 902775277.

Vitas A., Oszako T., Nowakowska J.A., Sikora K., Stankevičienė A., 2012 First records of Phytophthora spp. based on DNA analysis in Lithuania. Folia Forestalia Polonica, series A, 54(1): 25-31.

Webster M., Sheets H.D., 2010. A practical introduction to landmark-based geometric morphometrics. In: Alroy, J., Hunt G. (eds.), Quantitative methods in Paleontology. Paleontological society Short Course, The Paleontological Society Papers, vol 16, pp. 163-188.

Wilson L.A.B., Colombo M., Hanel R., Saltzburger W., Sánchez-Villagra M.R., 2013. Ecomorphological disparity in an adaptive radiation: opercular bone shape and stable isotopes in Antarctic ice fishes. Ecology and Evolution 3(9): 3166-3182. DOI: 10.1002/ece3.708. 
Zahn C.T., Roskies R.Z., 1972. Fourier descriptors for plane closed curves. IEEE Transactions, Computers 21: 269-281. DOI: 10.1109/TC.1972.5008949.

Zentmeyer G.A., Ribeiro O.K., 1977. The effect of visible and near-visible radiation on sporangium production by Phytophthora cinnamomi. Phytopathology 67(1): 9195. DOI: 10.1094/Phyto-67-91. 